\title{
Correspondence
}

\section{Regional anesthesia in cardiac surgery and immediate extubation after car- diac surgery: a different view}

To the Editor:

We read with great interest the editorial by Dr. Cheng. ${ }^{1}$

Dr. Cheng questions the economic benefit of immediate extubation after cardiac surgery in our prospective audit. ${ }^{2} \mathrm{He}$ states that the patients being transferred to the postanesthesia care unit (PACU) immediately after extubation needed a nurse cover of a ratio of $1: 1$ and mentions that this is more intensive than nurse : patient ratio in patients who arrive in the intensive care unit (ICU) intubated.

We would therefore like to stress the fact that in our ICU, patients arriving intubated/ventilated from the operating room $(\mathrm{OR})$ are dealt with on a nurse : patient ratio of $1: 1$, as is the case in the PACU immediately after surgery when the patients arrive extubated from the OR. Therefore, they do not need more nursing care than patients still intubated after cardiac surgery.

Dr. Cheng states that thoracic epidural analgesia (TEA) has been reported to provide no improvement in postoperative mobilization, spirometry function and hospital length of stay, based on one study. ${ }^{3}$ Scott et al. ${ }^{4}$ conducted a prospective, randomized and controlled study evaluating the incidence of organ complications in 420 patients undergoing routine coronary artery bypass grafting with or without TEA, and found a significantly lower rate of respiratory tract infections, and better pulmonary function as measured in maximal inspiratory lung volume in patients with TEA. Liem et al. ${ }^{5}$ in another, smaller study, found a significantly higher postoperative $\mathrm{PaO}_{2}$ whenever TEA was used.

The authors are surprised by Dr. Cheng's statement that complications after TEA include pruritus, nausea and vomiting and urinary retention. Pruritus, nausea and vomiting might occur whenever opioids are added to TEA, but are not related to TEA itself - in more than 400 cases of TEA with plain bupivacaine in our hospital setting, no patient experienced pruritus or nausea and vomiting related to TEA. Urinary retention might be a complication of lumbar TEA, but seems rather rare with high TEA. High TEA might actually improve renal function, ${ }^{6}$ or at least not be different from general anesthesia. ${ }^{7}$

Large multicentre prospective studies are required to further prove the benefits of TEA in cardiac surgery.

Thomas Hemmerling MD DEAA

Jean-Luc Choinière MD FRCPC

Fadi Basile MD FRCS

Ignatio Prieto MD FRCS

Hôtel-Dieu, Centre Hospitalier de l'Université de Montréal, Montréal, Canada

E-mail: thomashemmerling@hotmail.com

\section{References}

1 Cheng DC. Regional analgesia and ultra-fast-track cardiac anesthesia. Can J Anesth 2005; 52: 12-7.

2 Hemmerling TM, Prieto I, Choiniere JL, Basile F, Fortier JD. Ultra-fast-track anesthesia in off-pump coronary artery bypass grafting: a prospective audit comparing opioid-based anesthesia vs thoracic epiduralbased anesthesia. Can J Anesth 2004; 51: 163-8.

3 Priestley MC, Cope L, Halliwell R, et al. Thoracic epidural anesthesia for cardiac surgery: the effects on tracheal intubation time and length of hospital stay. Anesth Analg 2002; 94: 275-82.

4 Scott NB, Turfrey DJ, Ray DA, et al. A prospective randomized study of the potential benefits of thoracic epidural anesthesia and analgesia in patients undergoing coronary artery bypass grafting. Anesth Analg 2001; 93: 528-35.

5 Liem TH, Hasenbos MA, Booij LH, Gielen MJ. Coronary artery bypass grafting using two different anesthetic techniques: part 2: postoperative outcome. J Cardiothorac Vasc Anesth 1992; 6: 156-61.

6 Suleiman MY, Passannante AN, Onder RL, GreeneHelms WF, Perretta SG. Alteration of renal blood flow during epidural anesthesia in normal subjects. Anesth Analg 1997; 84: 1076-80.

7 Schenk HD, Radke J, Ensink FB, et al. Interactions between renal and general hemodynamics in fentanyl, droperidol, ketamine, thiopental and in peridural anesthesia--animal studies (German). Anaesthesiol Reanim 1995; 20: 60-70. 